\title{
The ethics of crowdsourcing
}

\section{Julie McDonough Dolmaya}

School of Translation, York University

Because crowdsourced translation initiatives rely on volunteer labour to support both for-profit and not-for-profit activities, they lead to questions about how participants are remunerated, how the perception of translation is affected, and how minority languages are impacted. Using examples of crowdsourced translation initiatives at non-profit and for-profit organizations, this paper explores various ethical questions that apply to translation performed by people who are not necessarily trained as translators or financially remunerated for their work. It argues that the ethics of a crowd-sourced translation initiative depend not just on whether the initiative is part of a not-for profit or a for-profit effort, but also on how the project is organized and described to the public. While some initiatives do enhance the visibility of translation, showcase its value to society, and help minor languages become more visible online, others devalue the work involved in the translation process, which in turn lowers the occupational status of professional translators.

\section{Introduction}

In June 2009, LinkedIn, the online professional networking platform, invited its members to complete a survey about their interest in translating the LinkedIn website. However, when respondents were asked what kinds of incentives they would expect, only non-monetary options were offered. These ranged from nothing ("because it's fun") to recognition on translation leaderboards/user profiles (e.g., "You're the \#1 translator of LinkedIn in French") or an upgraded LinkedIn account. ${ }^{1}$ Many professional translators (who represented about $50 \%$ of the 12,000 survey respondents) took offence to being asked to volunteer to translate for a commercial organization like LinkedIn, particularly one promoting itself as a networking site for professionals. ${ }^{2}$ LinkedIn, though, argued that it was simply exploring various translation options, that novice translators would likely be interested in volunteering to help build their reputations, that crowdsourcing would not, in fact, generate savings for LinkedIn given the cost to develop a translation interface system, that adopting such an approach would allow LinkedIn to translate quickly into many languages, and that professional translators would likely be hired to review the content 
and provide backup translations (Newman, 2009). ${ }^{3}$ The conflicting views of LinkedIn and these professional translators aptly illustrates the ethical questions surrounding crowdsourced translation, which is "undertaken by unspecified self-selected individuals" in digital media spaces (O'Hagan, 2009, p. 97) and is also called user-generated (O'Hagan, 2009; Perrino, 2009), open (Cronin, 2010), community (Kelly, 2009; Ray \& Kelly, 2011), and/or collaborative translation (Kelly, 2009; Ray \& Kelly, 2011).

In the two years following the LinkedIn controversy, similar questions have been discussed in various sources, including translator blogs (cf., McDonough Dolmaya, 2011), professional journals (e.g., Baer, 2010; Guyon, 2010; Dodd, 2011), industry reports (e.g., DePalma \& Kelly, 2008; Ray, 2009; Ray \& Kelly, 2011) and academic journals (e.g., O’Hagan, 2009; Perrino, 2009; Cronin, 2010). As one might expect, some professional translators share the same concerns as those offended by LinkedIn; Dodd, for instance, considers crowdsourcing "the exploitation of Internet-based social networks to aggregate mass quantities of unpaid labor" and worries this practice could lead to "a new apartheid economics of socialism for the workers, capitalism for the bosses” (Dodd, 2011, n.p.). Others, though, have been quite positive about the role of crowdsourcing in the industry and the changes this process brings to translation practice. For example, Baer (2010) argues that when crowdsourcing projects are effectively and appropriately designed, they can turn "what has been considered a threat to the translation industry" into a more acceptable and even positive model that "seed[s] collaboration between amateur and paid professional translators, provid[es] a training ground for new translation graduates, [and] expand[s] the material that gets translated, broadening access to information, and exposing more people to the translation process in all its complexity" (n.p.). Guyon (2010) pans crowdsourced translation interfaces, which often "[bear] no resemblance to the tools normally used by translators" and the fact that "for-profit corporations do not hesitate to cloak themselves in humanitarianism to convince the masses to translate their Internet products for free" (n.p.). However, he does laud the "nonhierarchized collaborative environment that is Wikipedia, [where] there are almost as many control mechanisms as there can be in the workplace, but with far more freedom of expression” (Guyon, 2010, n.p.).

This paper will critically examine the questions raised by these translation professionals, seeking not to provide definitive answers, but rather to examine several views and to study professional codes of ethics for insight. For reasons of space, three aspects of crowdsourced translation will be examined: participant remuneration, translation visibility, and the effect on minority languages. Together, these aspects encompass both the points raised by LinkedIn to justify its intention to crowdsource its website and the arguments professional translators have raised for and against crowdsourcing. 


\section{The ethical dilemmas posed by crowdsourcing}

\subsection{Remuneration}

When participant remuneration in crowdsourced translation initiatives is discussed, a distinction is usually made between initiatives launched by non-profit and for-profit organizations, with the latter often subject to criticism (e.g., Guyon, 2010; Dodd, 2011). Therefore, this paper will distinguish between three types of crowdsourcing models (proposed by Ray \& Kelly, 2011): product-driven, cause-driven, and outsourcing-driven. For the purposes of this paper, product-driven crowdsourced translation initiatives focus on localizing software or translating related documentation for free or open-source software projects, such as the productivity suite Open Office or the CAT tool OmegaT. Cause-driven initiatives centre around a project with a non-profit, often humanitarian mission. For instance, Global Voices Online is "a community of more than 300 bloggers and translators around the world who work together to bring you reports from blogs and citizen media everywhere, with emphasis on voices that are not ordinarily heard in international mainstream media,"4 while the TED Open Translation Project aims to subtitle talks from the TED website, which "offers free knowledge and inspiration from the world's most inspired thinkers. $"$ Finally, outsourcing-driven initiatives are launched by a for-profit company or organization that does not have a specific social or humanitarian mission but which does want to turn to the general public (namely its users) for its translating needs. Facebook and Twitter are both examples of companies that have launched outsourcing-driven initiatives.

Remuneration is such a thorny issue because it is tied to notions of professionalism: after all, as Chesterman (2001) argues, some people may not consider translation a true profession "because it does not seem to have a monopoly on a value goal that is not shared by other groups" (unlike medicine, with the goal of health or law, with the goal of justice) (p. 145); however, it is clearly a practice that "involves technical skills, is increasingly institutionalized, and seeks its own improvement via quality control systems and the training and accrediting of recruits" (p. 146). If translation is a skilled practice, then one should reasonably assume that translators deserve to be paid professional rates. For this reason, codes of practice from professional translator associations often address rates: the codes of the Asociación Guatemalteca de Intérpretes y Traductores, the Asociación Argentina de Traductores e Intérpretes and the Colegio de Traductores Públicos del Uruguay all oblige members not to charge fees significantly below specified rates; one Canadian association (the Ordre des traducteurs, terminologues et interprètes agréés du Québec) advises members to charge "fair and reasonable" fees, based on their experience, the difficulty of the text, and the importance of the project; the Irish Translators and Interpreters Association and the Spanish Asociación 
Española de Traductores, Correctores e Intérpretes (Asetrad) oblige members to avoid accepting work at rates of pay unreasonably below market norms; etc. (McDonough Dolmaya, 2011). But of course, as Chesterman (2001) acknowledges, such associations have little ability to restrict accreditation and thereby prevent amateurs or non-members from setting themselves up as translators; by extension, they also have little to no authority over whether and how amateurs or non-members choose to be remunerated for translation work.

Is it ethical, then, for an organization to seek volunteers to translate its website or products, and to offer non-monetary incentives for doing so? In the case of product- or cause-driven initiatives, many professional translators would likely say Yes. The Asetrad code of ethics, for instance, allows members to accept below-market rates when translating for nonprofit initiatives: in such cases members are obliged to inform clients of the market value of the translation work. Moreover, the fact that various professional translator networks such as Translators without Borders (TWB) and The Rosetta Foundation provide pro bono or heavily discounted services to not-for-profit organizations demonstrates the willingness of translators to volunteer their skills to support a mission or a social cause. Of course, motivations behind not-for-profit initiatives need to be critically examined: Baker (2006) notes that as an "offshoot of a commercial translation agency", TWB has conflicting humanitarian and commercial agendas (p. 159), but for reasons explored below, product- and cause-driven initiatives are not as ethically ambiguous as those launched by for-profit outsourcing-driven initiatives. ${ }^{6}$

If we look at how outsourcing-driven translation initiatives are often described, we get a sense of how for-profit companies are appealing to volunteers. Here are examples from initiatives launched between 2008 and 2011 by three social networking platforms:

The HootSuite Translation Project was launched in August, 2010 with a goal to unite HootSuite users all across the world and enable them to use their favorite social media tools in their native languages. [...] It's an easy to use, crowd-sourced project where a few hundred owls can work to help make thousands of international hoot-fans happy. (http://blog.hootsuite.com/ translation/)

The Translations application by Facebook allows translators all over the world to translate Facebook into different languages. Join our community of translators and make Facebook available to everyone, everywhere, in all languages. (http://www.facebook.com/translations/) 
Twitter has become a valuable tool for folks to exchange timely bits of information, whether it be a momentous news event, a personal story, or a random thought. We want everyone in the world to have the opportunity to engage in this important exchange, so we're calling on the help of real Twitterers to translate our site into their own language. You've helped define what's important about the product, so you should define your local experience, too. (http://support.twitter.com/articles/434816-abouttwitter-translate)

In such texts, two arguments encourage user participation. First, HootSuite, Facebook and Twitter appeal to users' sense of community. The "thousands of international hoot-fans" who will be made happy by the translated user interface are, just like the "few hundred" potential translators, existing HootSuite users. The international users are disadvantaged, however, since they cannot access HootSuite in their native language; HootSuite translators would therefore be helping out fellow community members. Facebook does not make this same argument, but it does depict the translators as a "community." Finally, Twitter clearly emphasizes the role users can play in shaping Twitter, telling them to "define [their] local experience." In this case, users are working together to create something from which they will all benefit: a local version of Twitter.

This appeal to a user's sense of community seems to support Howe's (2008) argument that:

What unites all successful crowdsourcing efforts is a deep commitment to the community. This entails much more than lip service and requires a drastic shift in the mind-set of a traditional corporation. The crowd wants to feel a sense of ownership over its creations, and is keenly aware when it is being exploited. The company, in this context, is just one more member of the community and you don't have to watch Survivor to know that people who act duplicitously are kicked off the island. (pp. 15-16)

Interestingly, in Howe's view, the people (i.e., the crowd) possess the power: they determine whether they are being exploited and refuse to contribute to the crowdsourcing effort if they feel this is the case. Yet, this argument is a little too simplistic: it places the onus almost entirely on the crowdsourcers rather than the companies behind the crowdsourced initiatives. If we follow Howe's argument to its logical conclusion, every crowdsourced translation initiative in which people are participating must be ethical, because if the participants felt they were being exploited, they wouldn't participate. But what if participants aren't seeing beyond the "community" argument when they decide to translate for companies like 
HootSuite, Twitter and Facebook?

After all, underlying these community-centred narratives is often a second argument: translators will help make the user interface accessible around the world to people outside the community. Thus, Twitter wants "everyone in the world to have the opportunity to engage in this important exchange," and Facebook translators will help "make Facebook available to everyone, everywhere." This latter argument is more problematic, as the companies are indicating that their motivations for translating their websites are not just a seemingly altruistic desire to give existing users a better experience (as the "community" narrative implies). A translated user interface will help Facebook, Twitter (and even HootSuite, although this is not explicitly mentioned) reach more users and therefore generate more revenue. Existing users may benefit from the translation by getting access to a "local" or "native-language" version, but the company benefits as well by getting access to users outside the existing community.

As Van Dijck \& Nieborg (2009) argue, though not about translation in particular:

[There is a] significant distinction between users of commercially driven online communities and not-for-profit, community-based exchange sites. [...] Most people who visit usergenerated content sites are 'driven' there by (viral) forms of social media ('friends' networks) or by plain marketing mechanisms. [...] What is designated as 'collectivity' or 'mass creativity' is often the result of hype from networking activity - a type of activity heavily pushed by commercially driven social platforms and aggregator sites. Established companies as well as e-commerce firms are looking for ways to engage with their customers online, to harness their knowledge potential and to engage in a meaningful dialogue. [...] To align all kinds of user motives for online participation as community driven is a rhetorical ploy popular among advertisers, who like to present telephone companies as being in the business of 'connecting people' or who promote credit card companies as 'facilitators of love and affection.' (pp. 863-864)

For Van Dijck \& Nieborg, then, participants might not even realize they're being exploited, because they're unable to see through the "marketing mechanisms", "hype”, and "rhetorical ploys." Moreover, because networks such as Facebook and Twitter do not cost any money to join, users may forget these services are earning (considerable) advertising revenue precisely because they are free. ${ }^{7}$ Users may thus feel obliged to "give back" to the (ostensibly) free communities, even though Facebook and Twitter are for-profit ventures. The entire crowdsourcing initiative becomes suspect, because its community-centred focus is a device used to generate interest, commitment and involvement with a brand or company, which ultimately 
helps attract more users and thereby generate more revenue for the company. Thus, it is difficult to say for sure whether participants who want to contribute are indeed willing or whether they have been driven to participate-at least in part-by various marketing mechanisms. This makes the ethics of these initiatives murky at best.

\subsection{Translation visibility}

Because participants in crowdsourced translation initiatives are typically not financially remunerated, their efforts are often recognized in other ways, including optional "translator" badges (e.g., Wikipedia, Twitter), links to the translator's website or profile page (e.g., TED Open Translation Project, Der Mundo, Facebook, HootSuite, Kiva), photos of translators (e.g., TED, Global Voices Online, Der Mundo, Facebook, Hootsuite), ${ }^{8}$ and translator leaderboards or top contributors page (e.g., HootSuite, Facebook, Twitter).

This kind of recognition provides visibility for more than just participating translators: as Cronin (2010) argues, crowdsourcing makes the general public more aware of the "demands of translation for large groups of global users” (2010, p. 4). As Dam \& Zethsen (2008) argue in their study of the perceived occupational status of in-house Danish translators, the visibility of a profession contributes to its status (pp. 74-75); thus, by publicizing the activities of volunteer translators, crowdsourcing initiatives are helping translation become a more visible practice.

Yet visibility alone will not make translation seen as a high-status profession. As Dam \& Zethsen note, educational requirements, money, power, worthiness and value to society are generally parameters Westerners associate with job prestige (p. 74). Crowdsourced translation initiatives usually do try to prove the worth of translation, as the above quotes from Facebook, HootSuite and Twitter demonstrate (it will help make Facebook "available to everyone, everywhere, in all languages", "thousands of international hoot-fans happy”, etc.) - after all, if participants could not be convinced translation was a worthwhile activity with value for the community, they would probably not volunteer for the task.

The problem lies with the other parameters, particularly educational requirements and money: in a crowdsourced translation initiative, the most visible work is done by unpaid volunteers who do not necessarily have any formal translation training. The consequences, though, are varied. Some initiatives stress the difficulty of translation (e.g., TED), ${ }^{9}$ implement a barrier to participation (e.g., Kiva, which gives applicants a translation test), and review submissions prior to publication (e.g., TED). Here, the status of translation is markedly higher, since the practice is depicted as beyond the skill of some people. Moreover, when the initiative is cause- or product-driven (as with TED and Kiva), the fact that participants are not financially remunerated is not as important, given the additional value of 
volunteering for a worthy cause, and the fact that translation is not the only unpaid activity. For instance, open-source software is created by volunteer developers, so it is not inappropriate for the translating to also be done by volunteers. Likewise, the TED Open Translation Project indicates that while translators are not paid, neither were the TED speakers whose videos are being subtitled. ${ }^{10}$ Such projects highlight the difficulty and value of translation and therefore help enhance its visibility in society. They also provide a platform for the general public to gain more exposure to translation, and for novice translators to gain more practical experience. O'Hagan (2009, p.110), for instance, has suggested that fan translation networks can provide training environments for novices, so crowdsourced initiatives such as TED or Kiva could act in a similar way, though more research in this area, such as surveys of volunteers to determine how many obtained paid opportunities due to their participation, is needed.

Other initiatives, though, stress the "fun" and "easy" aspects of translation (e.g., Flock Localization Program, ${ }^{11}$ Twitter), ${ }^{12}$ point out that anyone-regardless of their second-language skills-can participate (e.g., Traduwiki) ${ }^{13}$ and make the community responsible for quality control (e.g., Facebook), regardless of whether these users have any formal training in translation. Virtually all professional translator associations would object to this approach: seventeen codes of ethics studied by McDonough Dolmaya (2011) prohibit translators from accepting work for which they do not have the required competence, and six include restrictions on whether members should translate into a language they do not master like a native speaker. Moreover, when initiatives do not emphasize the difficulty of the translation process, the (generally amateur) bilinguals who participate are the visible face of translation, even if professional translators are hired to approve the final submissions, as sometimes happens (Baer, 2010). ${ }^{14}$ The public perception of translation may therefore be lowered: it is portrayed as a task easily accomplished by anyone who speaks more than one language, however competently. When such initiatives are also outsourcing-driven, participants are helping a for-profit company reach new markets rather than helping a not-for-profit organization advance a social or political cause, which reduces the "worthiness" parameter that would help raise translation's status. This, in turn, helps depict translation as a task requiring little formal training (since virtually any bilingual Internet user can contribute), more suitable for a hobby than a profession (since companies like Twitter, Facebook and HootSuite do not appear to be paying for such fun and easy work). ${ }^{15}$

\subsection{Translation and "minor" languages}

While crowdsourcing does not always enhance the visibility and status of 
translation, its user-generated (O’Hagan, 2009; Perrino, 2009) nature could help reduce the uneven way language versions of software and websites have traditionally been made available. As Esselink (2000) argues: "Historically, the largest markets for localized products have been France, Germany and Japan. Medium-sized markets include Brazil, Italy, Spain, Sweden, Norway, and the Netherlands. Software publishers typically localize their products into FIGS (French, Italian, German and Spanish) and Japanese first. Swedish, Norwegian, Danish, Dutch or Brazilian Portuguese often follow as second tier languages” (p. 8). Similarly, Pym has noted that the extent to which a product will be localized depends not only on the current or potential target market size, but also on the extent of diversity within the market (2004). Thus, when companies are deciding whether to localize their websites for a Spanish-speaking market, they base their decision not on just the number of potential users in Mexico, for instance, but also on how many users in other regions also speak Spanish, since relatively minor changes could make the Mexican version suitable for other Spanish-speaking markets. Spanish would therefore be a more lucrative language than Finnish, for instance, which is not spoken in many regions outside Finland. When languages are considered in this way, markets with a small number of potential customers will get less (if any) translated content than areas where users speak languages used in several other markets.

On the surface, the user-generated nature of crowdsourcing could change this trend: after all, if users would like a Finnish translation, they simply have to prepare it themselves, once the translation interface is made available. In fact, various crowdsourced translation initiatives allow users to suggest or add languages (e.g., anobii.com; TED; Wikipedia; Flock; ${ }^{16}$ OpenOffice; ${ }^{17}$ Global Voices Online; ${ }^{18}$ Twitter; ${ }^{19}$ Facebook). ${ }^{20}$ Accordingly, in some projects, "minor" languages are given the same attention as typical Tier 1 languages such as French, Italian, German and Spanish. ${ }^{21}$ Thus, by March 2011, TED Talks had been subtitled for more than 80 languages, and while the three languages with the most translated talks were Spanish, French and Brazilian Portuguese (with more than 800 talks each), Bulgarian was a close fourth. In fact, more talks were available in Romanian (700+), Polish (600+), Turkish (600+) and Hebrew (600+), than German (500+), Japanese (400+), Dutch (400+), Swedish (100+) or Danish $(50+){ }^{22}$ Global Voices Online, another cause-driven translation initiative has similar results: although only seventeen languages are listed as "regularly updated," several would be considered minor, including Malagasy, Serbian, Swahili, Macedonian, Bangla, and Indonesian. As the Global Voices Lingua page notes, "the languages chosen reflect the momentum in their community of speakers," meaning site users largely determine the languages chosen for translation, the frequency at which the translated sites are updated, and the amount of information available in a given language.

And yet, target languages will inevitably be prioritized, even if user demand drives the initiative. Languages with more speakers online will 
have a larger community from which to draw volunteers, and so Spanish, French and Portuguese speakers, for instance, are likely to complete their localized versions before Swahili speakers, even if an interface is made available to all four communities at the same time. This fact is exemplified by the HootSuite Translation Project page (http://translate.hootsuite.com/), where bar graphs indicate that languages such as Japanese, French, Spanish, and Italian are almost completed and have recent activity, while versions like Romanian, Polish, Persian, Welsh, Czech, Chinese and Ukrainian remain virtually untouched, with the last activity over a year earlier. Even Facebook, available in 64 languages within three years of the 2008 launch of its first translated version, began with Spanish and then added French and German several weeks later (Arrington, 2008) instead of opening up the application to dozens of languages at once. And project-

driven initiatives such as Thunderbird or OpenSolaris often have two or more language tiers with varying priority levels. ${ }^{23}$

Crowdsourced translation initiatives may appear to break down limitations on language availability (and in some cases, such as TED's Open Translation Project, they actually do result in major and minor languages receiving similar attention), but in some initiatives, they allow an organization to demonstrate its willingness to make a language version available, while making the community responsible for actually completing the translation. The fact that users request a target language does not mean it will ever be completed, nor does it automatically mean a minor language will be accessible before languages such as Spanish, French and German, the likely priorities of a non-crowdsourced project.

\section{Conclusions}

Clearly, the ethical implications of crowdsourced translation depend not just on whether the initiative supports an open-source project, a non-profit cause, or a for-profit service, but also on how the project is organized and described to the public. Although participants are generally not financially remunerated, crowdsourcing initiatives can still enhance the visibility of translation, showcase its value to society, and help minor languages become more visible online. Moreover, participants can still enjoy non-financial benefits: the satisfaction of supporting a cause, more exposure to the translation process, greater visibility for themselves as translators, etc.

On the other hand, it is difficult for outsourcing-driven translation initiatives to enhance the public perception of translation, particularly if such initiatives do not emphasize the skill and training involved in the process. This devalues the work involved in the translation process and contributes to lowering the occupational status of professional translators. This in turn challenges the idea that translation is a skilled practice 
requiring training, accreditation and quality control systems. Further, it affects the future of translation: by pushing professional translators into the shadows as the unseen and unknown revisers of the publicly visible (and often novice) volunteers, many crowdsourcing models are likely to leave only revision and consulting as areas of paid translation-related work, which may lead to this kind of work being seen as higher status activities than translation.

Finally, outsourcing-driven initiatives may appear to empower crowds, allowing them to determine what languages will be made available and how content will sound in the target language, but through marketing mechanisms, they also exploit participants' commitment to friends and family within the TL community, helping to make them feel they ought to help these TL speakers access website content in their own language. Moreover, these initiatives shift the responsibility for translation onto users, perhaps foreshadowing both a greater blurring of the distinction between translation consumers and producers, and a shift in the way translation is viewed, produced and received by Internet users, corporations, and translators themselves.

\section{References}

Arrington, M. (2008, January 21). Facebook taps users to create translated versions of site. Spanish, French and German available now. TechCrunch. Retrieved from http://techcrunch.com/2008/01/21/facebook-taps-users-to-create-translatedversions-of-site/

Baer, N. (2010, February 1). Crowdsourcing: Outrage or opportunity? Translorial: Journal of the Northern California Translators Association. Retrieved from http://translorial.com/2010/02/01/crowdsourcing-outrage-or-opportunity/

Baker, M. (2006). Translation and conflict: A narrative account. London: Routledge.

Boéri, J. (2008). A narrative account of the Babels vs. Naumann controversy: Competing perspectives on activism in conference interpreting. The Translator, 14(1), 21-50.

Chesterman, A. (2001). Proposal for a hieronymic oath. The Translator, 7(2), 139-154.

Cronin, M. (2010). The translation crowd. Revista tradumàtica, 8. Retrieved from http://www.fti.uab.cat/tradumatica/revista/num8/articles/04/04.pdf

Dam, H. V., \& Zethsen, K. K. (2008). Translator status: A study of Danish company translators. The Translator, 14(1), 71-96.

Depalma, D. A., \& Kelly, N. (2008). Translation of, for and by the people: How usertranslated content projects work in real-life. Lowell, Ma: Common Sense Advisory.

Dodd, S. M. (2011, January 1). Crowdsourcing: Social[ism] Media 2.0, Translorial: Journal of the Northern California Translators Association. Retrieved from http://translorial.com/2011/01/01/crowdsourcing-socialism-media-2-0/

Esselink, B. (2000). A practical guide to localization. Amsterdam: John Benjamins.

Guyon, A. (2010). The ups and downs of online collaborative translation. P. Beaudry (Translated into English. French original 'Grandeurs et misères de la traduction collaborative en ligne'). L'Actualité langagière, 7(1). Retrieved from http://www.btb.gc.ca/btb.php?lang=eng\&cont=1536

Howe, J. (2008). Crowdsourcing: Why the power of the crowd is driving the future of 
business. New York: Random House.

McDonough Dolmaya, J. (2011). A window into the profession: What translation blogs have to offer Translation Studies. The Translator, 17(1), 77-104.

McDonough Dolmaya, J. (2011). Moral ambiguity: Some shortcomings of professional codes of ethics for translators. Journal of Specialised Translation, 15, 28-49.

Newman, A. A. (2009, June 29). Translators wanted at LinkedIn. The pay? \$0 an hour. The New York Times, B2. Retrieved from http://www.nytimes.com/ 2009/06/29/technology/start-ups/29linkedin.html

O’Hagan, M. (2009). Evolution of user-generated translation: Fansubs, translation hacking and crowdsourcing. Journal Of Internationalisation and Localisation, 1(1), 94-121.

Perrino, S. (2009). User-generated translation: The future of translation in a Web 2.0 environment. Journal of Specialised Translation, 12, 55-78.

Pym, A. (2004). The moving text: Localization, translation and distribution. Amsterdam: John Benjamins.

Ray, R. (2009). Crowdsourcing: The crowd wants to help you reach new markets. Romainmôtier, Switzerland: Localization Industry Standards Association.

Ray, R., \& Kelly, N. (2011). Crowdsourced translation: Best practices for implementation. Lowell, Ma: Common Sense Advisory.

Sargent, Benjamin B. (2008, August 14). Community translation lifts Facebook to top of social networking world. Common Sense Advisory Blogs. Retrieved from http://www.commonsenseadvisory.com/Default.aspx?Contenttype=ArticleDetA D\&tabID=63\&Aid $=525 \&$ moduleId $=391$

Van Dijck, J., \& Nieborg, D. (2009). Wikinomics and its discontents: A critical analysis of Web 2.0 business manifestos. New Media \& Society, 11(5), 855-874.

1 The survey question is reproduced in the blog post Spanish/English translator Matthew Bennett wrote on the topic: http://www.matthewbennett.es/1094/crowdsourcing-translations-andlinkedin-a-response-to-the-global-watchtower-opinion/. The results of this survey question, along with a discussion between blog readers and LinkedIn representative Nico Posner, are published on LinkedIn's blog at: http://blog.linkedin.com/2009/06/19/nico-posner-translatinglinkedin-into-many-languages/

2 By March 2011, the Translators against Crowdsourcing by Commercial Businesses Group at LinkedIn had over 450 members. See its profile page at: http://www.linkedin.com/ groups?about=\&gid=2032092\&trk=anet_ug_grppro

3 LinkedIn's response to Matthew Bennett's first blog post about the survey is available on Bennett's blog at: http://www.matthewbennett.es/1084/linkedin-infuriates-professionaltranslators-10-big-questions/

4 From the Global Voices Online About page at: http://globalvoicesonline.org/about/

5 From the TED About page at: http://www.ted.com/pages/about

$6 \quad$ Not all professional translators agree that having volunteers translate for non-profit causes or social movements is appropriate. Boéri (2008), for instance, analyzes the letter professional interpreter Peter Naumann published in AIIC's online journal Communicate regarding the World Social Forum's reliance on volunteer network Babels for its interpreting needs. In this letter, Boéri argues, Naumann paralleled "the glorious past of the profession" and "the dark ages brought about by capitalism and commodification, featuring a decline in quality and standards, superficial education and ignorant interpreters, and projected as a permanent threat to the profession” (2008: 39). Similar arguments are often used by professional translators 
against crowdsourced translation (e.g., many of the bloggers discussed in McDonough Dolmaya 2011).

7 This is because sites with a larger community of users will attract more advertisers. According to a March 19, 2011 article in Canadian newspaper The Financial Post, Facebook earned \$0.74 billion US from advertising revenue in 2009, and \$1.86 billion in 2010. Twitter earned \$45 million US from advertising revenue in 2010 and was expected to earn \$151 million in 2011. See http://ht.ly/4hOu6

8 Kiva, TED and Global Voices Online, for instance, credit all translated texts, providing (optional) photos of translators and links to profile pages with whatever personal or professional details translators would like to share. See, for instance, http://www.kiva.org/lend/232136, http://www.kiva.org/lend/232195 and http://www.kiva.org/lend/229118 and these translations from the Global Voices Online Spanish and French sites: http://es.globalvoicesonline.org/2010/11/12/india-obamamania/, http://es.globalvoicesonline.org/2010/11/12/blogueando-desde-la-infancia-plan-ceibal-es-unahistoria-de-exito/ and http://fr.globalvoicesonline.org/2010/11/11/48730/.

9 The Style Guidelines page notes that "TED doesn't require translators to have any formal training, but we do ask that you be fluently bilingual, and that you take seriously the role of translating another person's ideas.” It asks potential translators to consider how often they read, speak and write in the target language, adding that "If you find your skills are a bit rusty, you don’t necessarily have to disqualify yourself. But you should commit to the research and time it will take to achieve an accurate translation. (It helps to have a pool of fluent friends and family on-hand.)" see: http://www.ted.com/pages/view/id/295

10 See http://www.ted.com/pages/view/id/293

11 See the Flock L10n website: https://sites.google.com/a/flock.com/flock-l10n/home

12 According to the About Twitter Translate page: "Using the Translation Center is a fun and easy way for you to help make Twitter accessible to more people around the world" (see: http://support.twitter.com/articles/434816-about-twitter-translate)

13 As Traduwiki explains: "By saying anybody can translate, we really mean it. Traduwiki hashes each text into smaller chunks. They're limited to 2 phrases maximum. Each text contains lots of short, easy to understand phrases. Usually, those phrases are grouped together. Even though you think you don't know master [sic] a language enough to use it, you can get the meaning of those phrases and thus, are able to translate them.” See: http://traduwiki.org/About/About

14 Twitter, for instance, indicates that "Once we've collected a good number of translations for every phrase across the site, we will review them and pick the most accurate one.” (see: http://support.twitter.com/articles/434816-about-twitter-translate)

15 Sargeant (2008) argues that because for-profit companies such as Facebook had to pay to develop the translation interface, they are not saving money by adopting the crowdsourced translation model. However, the money they have invested in the translation interface has not gone to the participants, who are the publicly visible translators. This helps lower the status of translation, since it does not appear to be worth paying for, while IT is.

16 See the Localization Community Site at: https://sites.google.com/a/flock.com/flock110n/home/how-to-translate-flock

17 See the OpenOffice Languages page at: http://wiki.services.openoffice.org/wiki/Languages. Users are able to add languages to the list and contact a mailing list if the language they would like to work with is not on the list. 
18 The Global Voices Lingua page notes: "Any additional languages for which there is momentum will be added to Lingua.” See: http://globalvoicesonline.org/lingua/\#get-involved

19 The Twitter Translation Center page (http://translate.twttr.com/welcome) tells users: "Don't see your language? We're continually reviewing the list of languages we support, and would love your feedback."

20 A 2008 blog post by Facebook designer Chad Little indicated that 55 additional languages had been added to the Facebook Translation Application based on user demand. http://blog.facebook.com/blog.php?post=20734392130

21 Here, "minor" is used to refer to languages that, due to the size of the market, are not typically considered "Tier 1" or “Tier 2." These are languages that, compared to English, Spanish or French (spoken by many people in several large markets), are less lucrative investments, and are therefore usually given a lower priority in localization efforts.

22 Indeed, as the TED Open Translation Project webpage indicates, TED's approach "allows speakers of less-dominant languages an equal opportunity to spread ideas within their communities." See http://www.ted.com/pages/287

23 The OpenSolaris supports three languages tiers: Tier 1 (English, French, German, Japanese, Simplified Chinese, Spanish) and Tier 2 (Brazilian Portuguese, Italian, Korean, Russian, Traditional Chinese) languages receive full localization support, while dozens of others are internationalized but not fully localized. See http://hub.opensolaris.org/bin/view/Community+Group+int_localization/OpenSolaris201003T estPlan The Thunderbird localization page designates 10 languages (German, French, Japanese, British English, Spanish, Italian, Polish, Russian, Dutch, and Brazilian Portuguese) as Tier 1, meaning that the US English version of Thunderbird will not be released unless all Tier 1 language versions are also ready. All others languages are Tier 2 and will not delay Thunderbird's release. See https://developer.mozilla.org/en/Thunderbird_Localization 